Instructions for authors, subscriptions and further details:

http://brac.hipatiapress.com

\title{
Devenir Sculpteur (à Bourgeois) (c)
}

Salvador Juanpere ${ }^{1}$

1) Artista visual

Date of publication: February $3^{\text {rd }}, 2019$

Edition period: February 2019-June 2019

To cite this article: Salvador Juanpere (2019). Devenir Sculpteur (à Bourgeois). Barcelona, Research, Art, Creation, 7(1), 1-9. doi: 10.17583/brac.2019.3789

To link this article: http://dx.doi.org/10.17583/brac.2019.3789

\section{PLEASE SCROLL DOWN FOR ARTICLE}

The terms and conditions of use are related to the Open Journal System and to Creative Commons Attribution License (CC-BY). 
Chacue jour; vous dever renoncer a votice passé ou

l'accepter; et si vous

$$
\text { ne pouver pas }
$$

l'accepter, vous devenez un sculpteur. 
Chacyue jour, vous dever renoncer a votie passé ou

l'accepter, et si vous

$$
\text { ne pouver pas }
$$

l'accepter, vous devenez un sculpteur. 
Chacyue jour, vous dever renoncer a votice passé ou

l'accepter, et si vous ne pouver pas

l'accepter, vous devenez un sculpteur. 


\section{Chacyue jour, vous}

devez renoncet a

\section{votie passegon}

l'accepter; et si vous

ne pouver pas

l'accepter, vous deve-

nez un sculpteur. 


$$
\begin{aligned}
& \text { Chacule jetrityous } \\
& \text { dever renoncel a } \\
& \text { l'accepter; et si vous } \\
& \text { ne pouvez pass }
\end{aligned}
$$




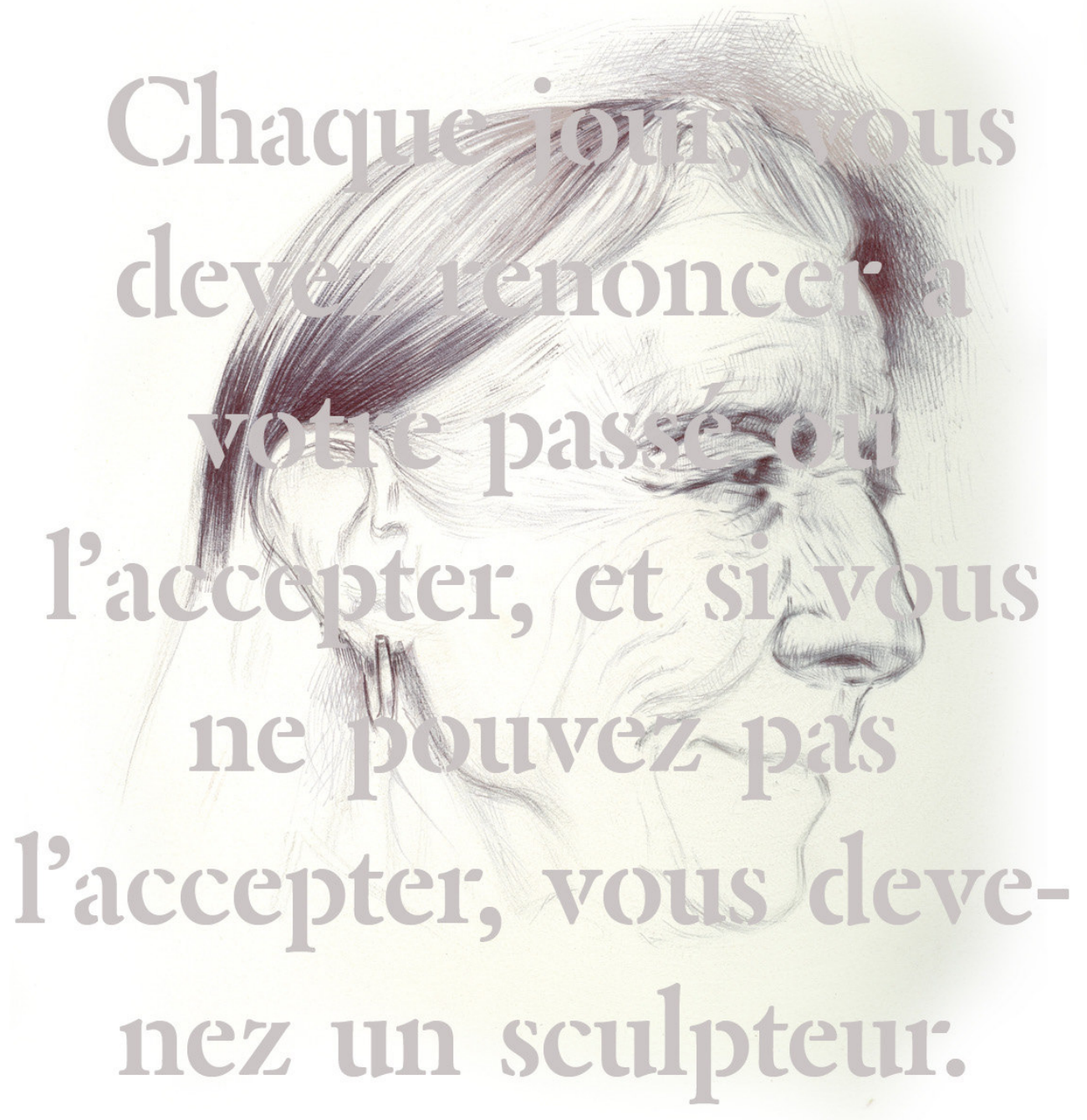




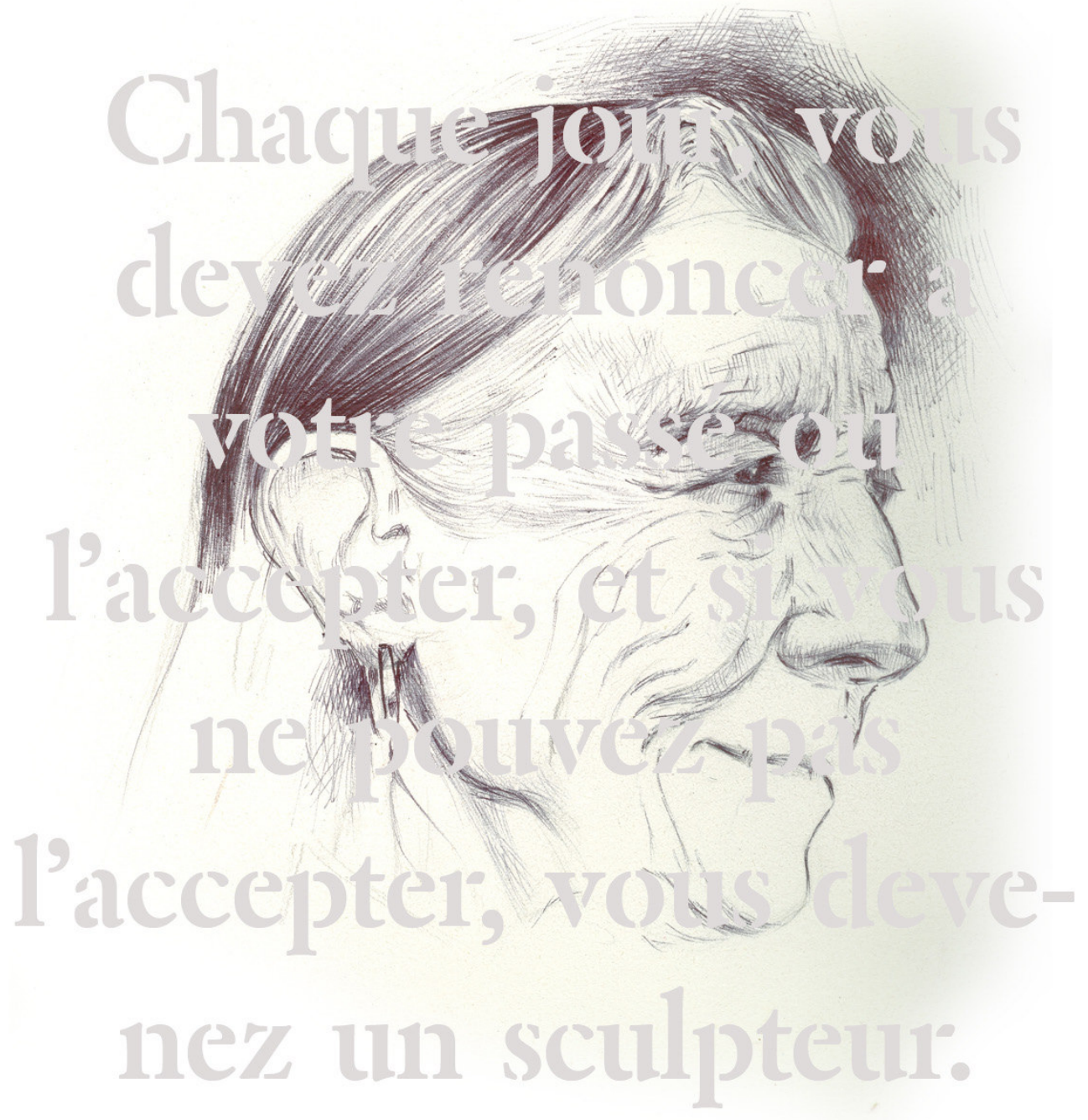




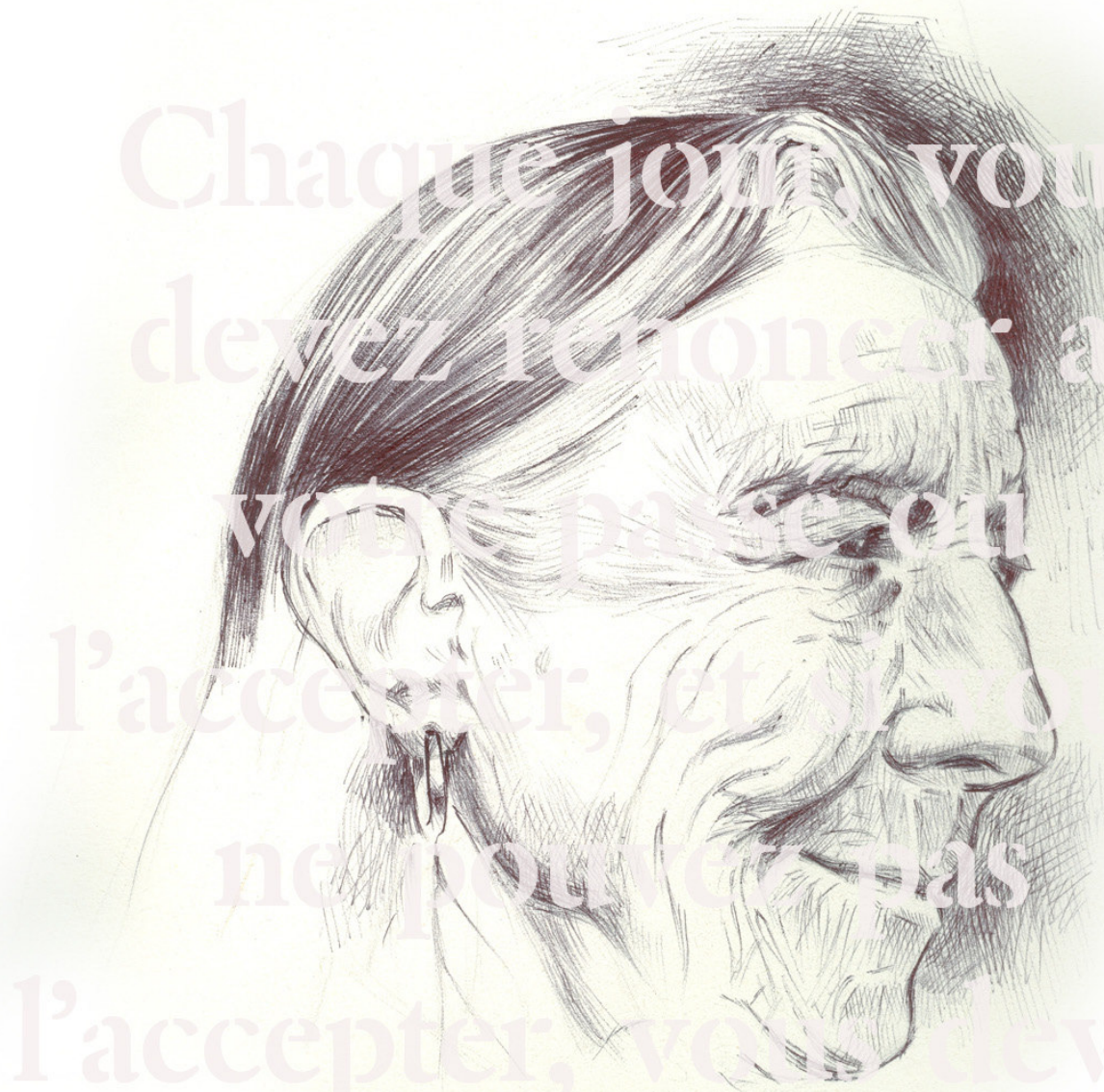




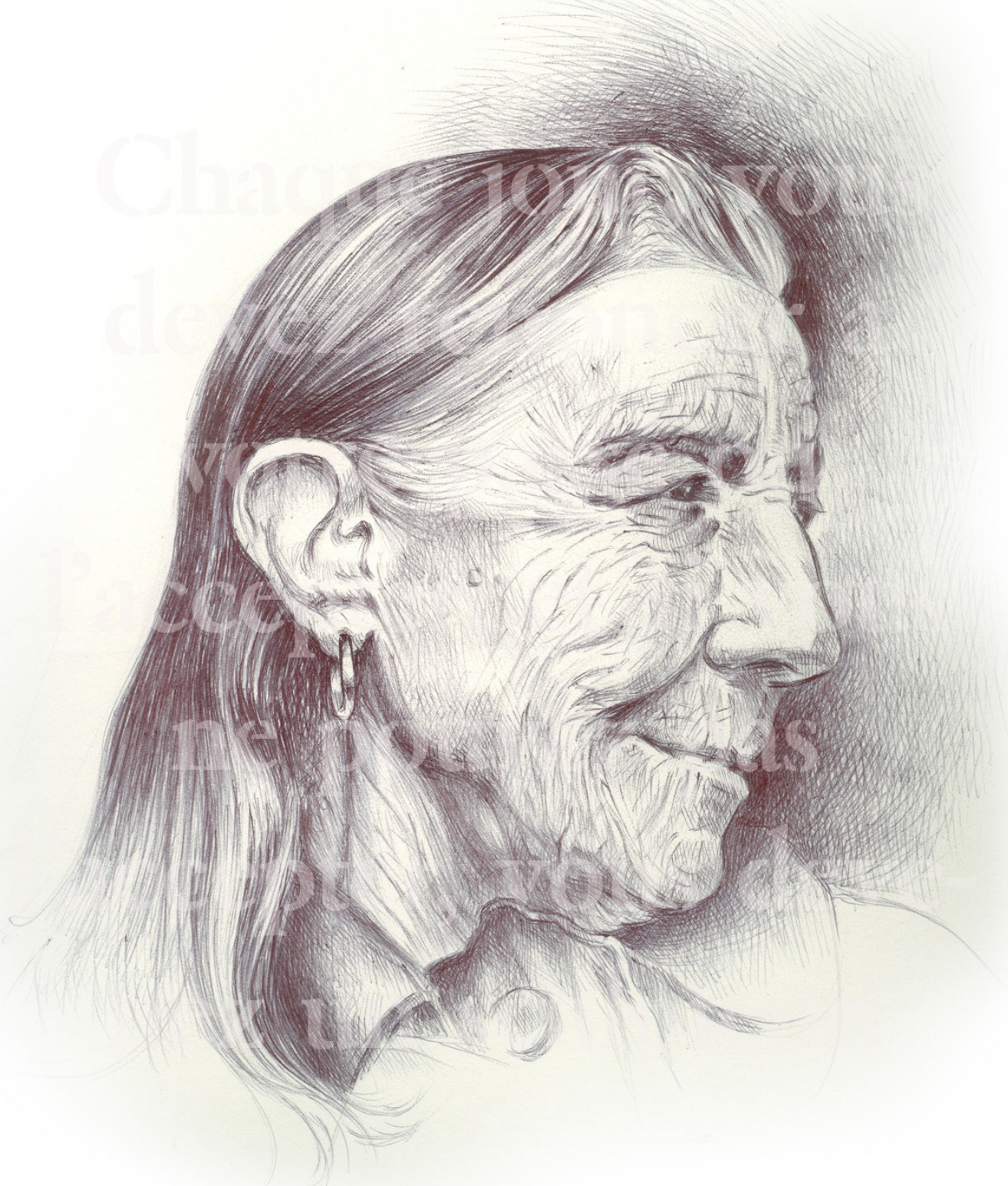

Devenir sculpteur (a Bourgeois). Dibuix i text. Salvador Juanpere 